\title{
Design and Optimization of a Diffuser for a Horizontal Axis Hydrokinetic Turbine using Computational Fluid Dynamics based Surrogate Modelling
}

\author{
Waleed KHALID*, Salma SHERBAZ**, Adnan MAQSOOD***, Zamir HUSSAIN**** \\ * Research Center for Modeling \& Simulation (RCMS), National University of Sciences and Technology (NUST), H-12 \\ Islamabad, Pakistan, Email: khalidbinwaleed97@gmail.com \\ **Research Center for Modeling \& Simulation (RCMS), National University of Sciences and Technology (NUST), H-12 \\ Islamabad, Pakistan,Email: salmasherbaz@rcms.nust.edu.pk \\ ***Research Center for Modeling \& Simulation (RCMS), National University of Sciences and Technology (NUST), H-12 \\ Islamabad, Pakistan, Email: adnan@rcms.nust.edu.pk \\ ****Research Center for Modeling \& Simulation (RCMS), National University of Sciences and Technology (NUST), H-12 \\ Islamabad, Pakistan, Email: zamir@rcms.nust.edu.pk
}

cross'ref http://dx.doi.org/10.5755/j01.mech.26.2.23511

\section{Introduction}

Fossil fuels have been considered as a major energy source for the global economic engine. In one way or the other, nearly all the industries and domestic units rely on energy produced by fossil fuels. With ever-increasing population and urbanization; the burden on fossil fuels has equivalently been increasing and will continue to do so until viable alternates are available. The fossil fuels have also caused degradation of our environment. This damage to the global climate has reached an alarming point and its impact has already been felt in recent decades. Carbon dioxide $\mathrm{CO}_{2}$ is the major anthropogenic greenhouse gas (GHG). The contribution of $\mathrm{CO}_{2}$ emissions from industrial processes and fossil fuel combustion accounted for about $76 \%$ of the total anthropogenic GHG emissions increase between 1970 and 2010 [1]. Lately, the governments around the globe, with the cooperation of the United Nations (UN) and regulatory bodies, are paying an ever-increasing attention to the environmental issues associated with fossil fuels.

The forecasted issues can only be resolved by shifting to alternate energy options having a lower carbon footprint. Ideally, these energy options are to be renewable in order to be sustainable in the longer run. Renewable energy sources, including, the sun, winds, water, biomass and geothermal, have shown significant promise in helping to reduce the amount of toxins produced by fossil fuel consumption.

Hydrokinetic energy, referring to the kinetic energy in moving water such as river, tide and ocean current, is a great resource of vast untapped environment-friendly renewable energy. There has been a major increase in hydrokinetic energy development and researchers around the globe are finding new ways to use this energy [2]-[7]. Horizontal axis hydrokinetic turbine (HAHT) is probably one of the most promising hydrokinetic energy technologies due high power output per unit and economic viability [8], [9]. The available energy in a water stream is directly proportional to the cube of incoming water velocity and a minor rise in the velocity is expected to have a significant effect on its energy density. Therefore the power output of a conventional bare turbine can be further improved by enclosing it within a diffuser, which accelerates the incoming flow [10].
Since last decade, there has been increasing trend/ focus on diffuser augmented HAHT. The advantage is significant since this makes HAHT installation viable in regions with slow flow velocity and offers higher power output from already viable/operational sites.

There is an increasing trend/ focus on designing HAHT with different diffusers design which can be divided into two broad categories (as shown in Fig. 1).

- Straight wall or curved plate diffusers with or without flanges;

- Diffusers based on annular airfoils with or without slots.

Gaden and Bibeau [11] reported an increase in power output of the bare turbine by a factor of 3.1 upon using a straight wall diffuser having a conical outlet. Kirke [12] in a towing tank experiment, observed approximately $70 \%$ increase in output power with a slotted diffuser. Gaden and Bibeau [13] optimized the shape of straight wall diffuser by varying the area ratio (outlet area/inlet area), and the diffuser angle. Shives and Crawford [14] studied potential augmentation of power output associated with ducted turbines using the extended version of boundary element method (BEM) and CFD techniques. The ducts were created by modifying NACA0015 airfoil using a series of transformations. Sun and Kyozuka [15] measured impact of a curved plate brimmed diffuser on the flow field of a tidal turbine. The performance of a bare and the shrouded turbine was analysed using experiment, computational fluid dynamics (CFD), and Blade Element Momentum (BEM) theory. Lokocz [16] performed an experimental investigation of ducted and a bare axial flow tidal turbine. NACA 4412 airfoil profile was used for the diffuser cross-section. Khunthongjan and Janyalert dun [17] studied diffuser angle effects on the performance of a flanged straight wall diffuser using CFD techniques. Mehmood et al. [18-20]optimized the performance of empty diffusers (based on different NACA hydrofoils) by varying both chord length and angle of attack using CFD techniques. Luquet et al. [21] used model testing and Reynolds-Averaged Navier-Stokes (RANS) equations based numerical calculations to study the increase in the flow rate through the rotor of a diffuser augmented current turbine after optimizing the design of airfoil based diffuser. It was observed that an optimum design of 
the diffuser can help in achieving a high power coefficient of 0.75 . The results of the numerical study conducted by Shinomiya et al. [22] confirmed the increase the efficiency of a conventional horizontal axis turbine due to the addition of diffuser. The flow around the three different diffusers geometries (curved plate and straight wall diffusers with and without brims) was simulated using finite volume method based software Ansys - Fluent. The computed numerical results were validated against the available experimental data. The results showed that the speed of the incoming flow in rotor plane of the diffuser augmented turbine was 1.5 timesmore than that of bare turbine. Ait-Mohammed et al. [23] observed a significant improvement in the hydrodynamic performance of a marine turbine due to the addition of a duct. The potential theory based panel method was used for this purpose. The duct was designed using NACA-4424 profile. The focus of the study conducted by Shi et al. [24] was the designed and optimization of a thin-wall curved plate diffuser of a horizontal axis tidal turbine using CFD methods and model testing. The two independent factors considered during the optimization study were the diffuser
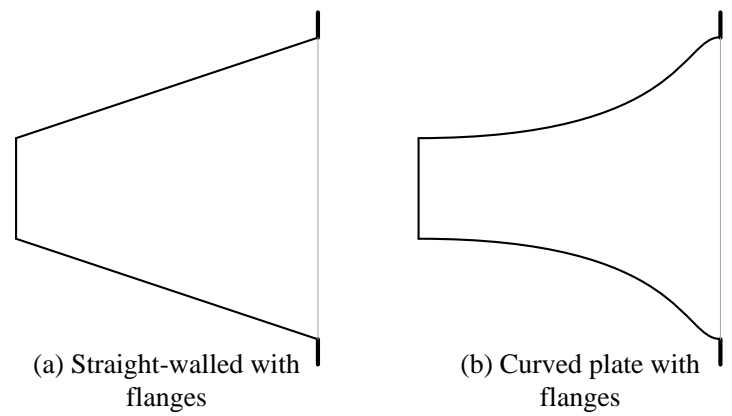

outlet diameter and expansion section length. Riglin et al. [25] investigated the performance characteristics of two thin wall curved plate diffuser designs (having area ratio of 1.36 and 2.01) for a micro hydrokinetic turbine using experimental testing and computational fluid dynamic techniques. Oblas [26] optimized the performance of a thin diffuser at a given flow rate for a hydrokinetic turbine unit for river application. Tampier et al. [27] used RANS based CFD simulation to study the interaction between rotor and annular ring shaped diffuser. The percent increase in the extracted power and thrust due to the diffuser augmentation was reported to be $39.37 \%$ and $26.15 \%$ respectively. The diffuser was designed using asymmetrical NACA airfoil having an angle of attack of $15^{\circ}$. Nunes et al. [28] performed the wind tunnel testing to evaluate the hydrodynamic performance of a 4bladed diffuser augmented hydrokinetic turbine. The two different diffuser geometries considered in the present case include a curved plate diffuser with brims and annular diffuser. A significant augmentation of the power coefficient was observed with the diffuser configuration.
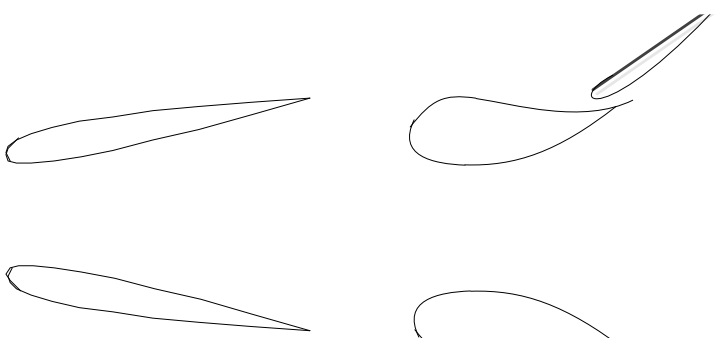

(c) Annular Shaped without Slots

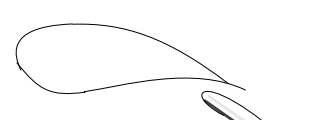

(d) Annular Shaped with Slots

Fig. 1 Diffuser design

The work done on diffuser augmented HAHT so far shows that the advantages of using a diffuser are recognized. However, the diffuser augmented HAHT has only been around for a little over a decade, so it is expected that the research work so far is still in establishing stage and mature approaches for diffuser design are under research, conceptualization or yet to come.

The most of the annular shaped diffuser designs for HAHT applications so far, have been based on standard NACA airfoils. Although this work has generated promising results, i.e. significant increase in power output, these airfoils are designed for high flow speed applications. The diffuser based on low flow speed hydrofoil will be ideal for HAHT applications. The aim of this study is the design and optimization of a diffuser for HAHT applications. The low Reynolds number flat plate airfoil is taken as baseline geometry. The flow around the two-dimensional airfoil is simulated using the commercial CFD software Ansys Fluent. The numerically computed results are compared with the available experimental data. Later, CFD analyses are carried out for baseline diffuser generated from the flat plate airfoil. The performance of this diffuser was optimized by achieving an optimum curved profile at the internal surface of the diffuser. Bezier curve parameterization and design of experiment (DOE) techniques are used for this purpose. The response surface methodology (RSM) is used as a tool for optimization.

\section{Governing equations}

In the present study two-dimensional, incompressible, steady state simulations are performed. The governing equations are as follows:

$$
\begin{gathered}
\frac{\partial U_{i}}{\partial x_{i}}=0, \\
\rho U_{j} \frac{\partial U_{i}}{\partial x_{j}}=-\frac{\partial p}{\partial x_{i}}+\frac{\partial}{\partial x_{j}}\left\{\rho v\left(\frac{\partial U_{i}}{\partial x_{j}}+\frac{\partial U_{j}}{\partial x_{i}}-\rho \overline{u_{i}^{\prime} u_{j}^{\prime}}\right)\right\},
\end{gathered}
$$

here: $\rho, p, U_{i}$ and $u_{i}^{\prime}$ are density, pressure, mean velocity, turbulent fluctuation, respectively. The term $-\rho \overline{u_{i}^{\prime} u_{j}^{\prime}}$ in above equation is called Reynolds stress [29].

The choice of a suitable turbulence model for a specific application is important for any flow problem. Thus, the profound understanding of all turbulence models along with their capabilities and limitations is important. The Spalart-Allmaras model is widely used in aerospace applications for studying the wall bounded flows with adverse pressure gradients[30]. It is a low-cost RANS model which solves a transport equation for the turbulent (eddy) viscosity. The one-equation model is given by the following equation [31]. 


$$
\begin{aligned}
& \rho U_{j} \frac{\partial \tilde{v}}{\partial x_{j}}=c_{b 1} \tilde{s} \tilde{v}+\frac{1}{\sigma} \frac{\partial}{\partial x_{k}}\left[(v+\tilde{v}) \frac{\partial \tilde{v}}{\partial x_{k}}\right]+ \\
& +\frac{c_{b 2}}{\sigma} \frac{\partial \tilde{v}}{\partial x_{k}} \frac{\partial \tilde{v}}{\partial x_{k}} c_{w 1} f_{w}\left[\frac{\tilde{v}}{d}\right]^{2} .
\end{aligned}
$$

\section{Model geometry, mesh generation and boundary con- ditions}

The baseline geometry used in the current case is flat plate airfoil with $1.96 \%$ thickness-to-chord ratio, a 5to-1 elliptical leading edge, and a sharp trailing edge (as shown in Fig. 2). A similar geometry was used by Mueller for his experimental testing [32]. Grid generation software Gambit is used to create the model geometry and mesh.

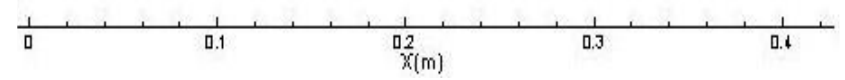

Fig. 2 Flat plate airfoil geometry

Any CFD simulation requires a high quality mesh for fast convergence, high solution accuracy and reduced computational time. Four node quadrilateral elements are used for meshing 2D analysis domain in the current study. Computational domain around the airfoil is of the rectangular shape. The inlet and outlet boundaries are located at a distance of $7 c$ and $14 c$ from the airfoil leading and trailing edges respectively ( $c$ is the cord length of airfoil). Similarly, the computational domain is extended $7 c$ above and $7 c$ below the airfoil (as shown in Fig. 3).

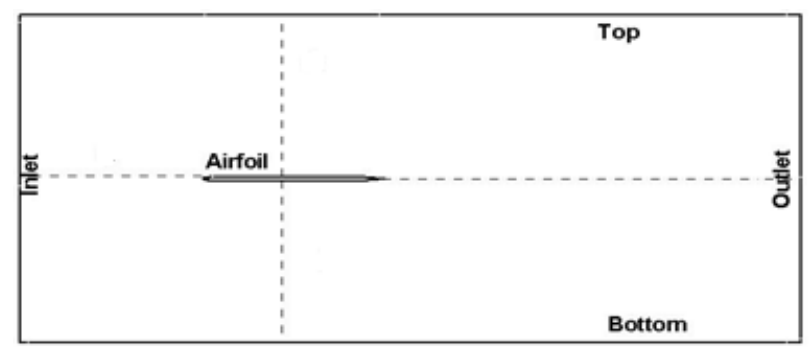

a

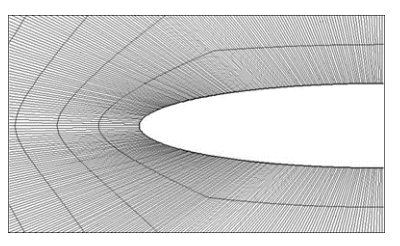

b

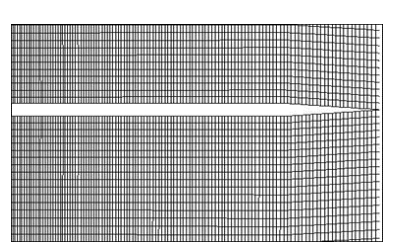

c
Fig. 3 Computational domain, boundary conditions and mesh around flatplate airfoil: a) Computational domain around the flatplate airfoil; b) Zoomed in view of mesh around flatplate airfoil leading edge; c) Zoomed in view of the mesh around flatplate airfoil trailing edge

In order to perform the mesh independence study, three systematically refining mesh schemes have been considered (shown in Fig. 4) by increasing the number of nodes on the airfoil surface (details are presented in Table 1). Since better computational accuracy is vital in the regions close to the airfoil surfaces, mesh resolution kept higher in these areas.
Table 1

Parameters of mesh independence study

\begin{tabular}{|c|c|c|}
\hline Grid & Total no. of cells & $\begin{array}{c}\text { No. of cells on airfoil sur- } \\
\text { face }\end{array}$ \\
\hline Coarse & 24000 & 100 \\
\hline $\begin{array}{c}\text { Me- } \\
\text { dium }\end{array}$ & 60000 & 200 \\
\hline Fine & 114000 & 300 \\
\hline
\end{tabular}

In addition, to keep the calculated value of wall $y^{+}$ in an acceptable range, the distance of the first node from the wall is calculated using the below formula:

$$
\Delta y=\frac{y^{+} \mu}{\mu_{t} \rho}
$$

where:

$$
U_{\tau}=\sqrt{\frac{\tau_{w}}{\rho}}, \tau_{w}=\frac{1}{2} c_{f} \rho U_{\infty}^{2}, c_{f}=0.058 \mathrm{Re}^{-0.2},
$$

where: $L$ is the flow characteristic length scale, $y^{+}$is the desired $y^{+}$value and $R e$ is the Reynolds Number. Since the $y^{+}$ is dependent on the local fluid velocity, which varies significantly across the air foil surface, it is impossible to know exact the value $y^{+}$prior to running an initial simulation. However, a good initial estimate of the first node distribution can be achieved through this method.

A uniform velocity profiles were prescribed as inlet boundary conditions. At the outlet, the pressure outlet boundary condition with outlet pressure same as atmospheric pressure, was applied. For, inlet and outlet boundary condition, the turbulence intensity and turbulence viscosity ratios were set to 0.07 and 0.001 respectively. The symmetric condition was adopted (for flow in a diffuser) on the symmetry plane. No-slip boundary condition was used on the air foil.

\section{Solver settings}

The flow field is computed by solving the $2 \mathrm{D}$ Reynolds averaged Navier-Stokes (RANS) equations using the general purpose code Fluent 16, 2ddp (two-dimensional with double precision). Fluent pressure based solver is used. This solver takes momentum and pressure (or pressure correction) as the primary variables and the continuity equation is reformatted for deriving pressure-velocity coupling algorithms. Five algorithms for pressure-velocity coupling available in fluent are Semi-Implicit Method for PressureLinked Equations (SIMPLE), SIMPLE-Consistent (SIMPLEC), Pressure-Implicit with Splitting of Operators (PISO), Coupled, and Fractional Step Method (FSM). All of these algorithms except 'Coupled' use the predictor-corrector approach and each one is suitable for a variety of flow problems. The well-known SIMPLE algorithm is used in the current study. Second-order-upwind interpolation schemes have been used for convection terms. The second order scheme provides an improved computational accuracy by reducing numerical diffusion error. The convergence of the left and drag coefficients along the residual history is monitored to examine the iterative convergence. The residuals 
are one of the most important measures to assure the convergence of an iterative CFD simulation, since they repre- sent the local imbalance of a conserved variable in each control volume. A root mean square (RMS) residual value of $10^{-6}$ is adopted as the stopping criteria for the current study.

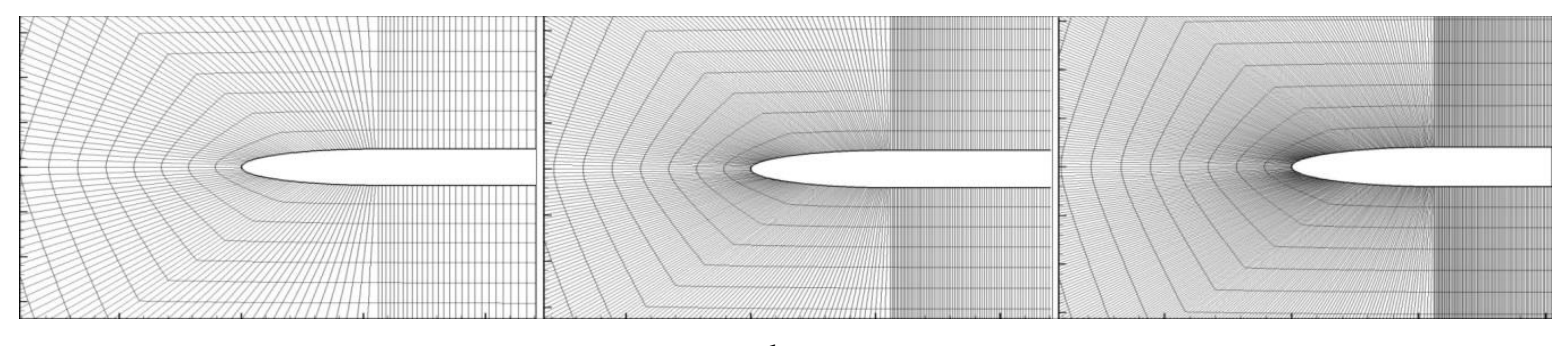

a

b

c

Fig. 4 Computational mesh around flatplate airfoil leading edge: a) Coarse mesh; b) Medium mesh; c) Fine mesh

\section{Results and discussion}

\subsection{Benchmark validation}

Extensive experimental/numerical data is available for 2-D flat plate airfoil for comparison and initial validation33. Steady-state simulations are performed at a free stream velocity of $7.84 \mathrm{~m} / \mathrm{s}$ (based on the Reynolds number of 100,000) and various angles of attack (ranging from 0o8o). The density and viscosity of air are $1.77 \mathrm{kgm}^{-3}$ and $1.846 \times 10^{-5}$ respectively. The numerical simulations are performed on RCMS super computer using 4 compute nodes (each node consisted of 8 processors), available at Supercomputing Research and Education Center (ScREC), RCMS, NUST. The comparison between the computed and available results of lift and drag coefficients at different angles of attack is shown in Fig. 5.

It can be seen that the simulated results are in good agreement with available data. The contours of the velocity magnitude for flat-plate airfoil at three different angles of attack are displayed in the Fig. 6 showing larger separation zone at a higher angle of attack.

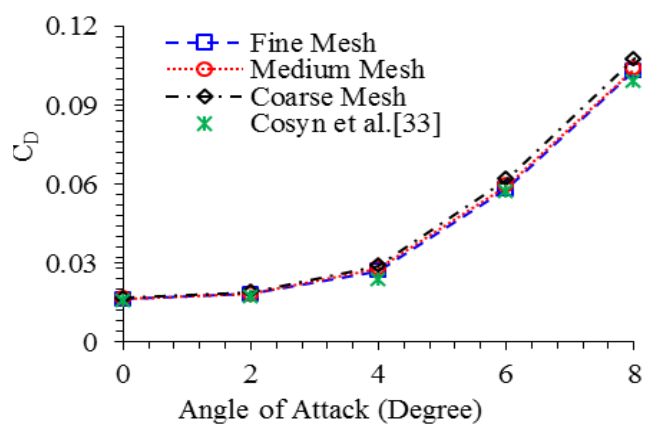

a

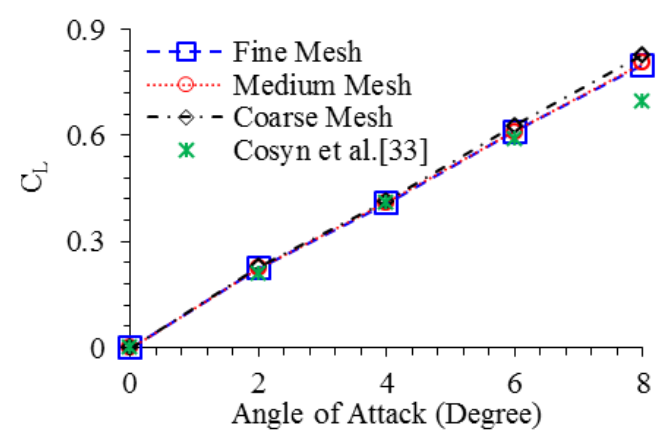

$\mathrm{b}$

Fig. 5 a) Drag coefficient vs. angle of attack; b) Lift coefficient vs. angle of attack

\subsubsection{Grid convergence study}

As mentioned earlier, in order to perform a grid convergence study, mesh parameters on the airfoil surface were varied to create three meshes. The Grid Convergence Index (GCI) is used as a measure to assess the relative discretization error in the simulated results. Based on the Richardson Extrapolation, GCI is considered as the most reliable method for the assessing the grid convergence errors associated with the numerical solution of partial differential equations. It demonstrates how far the solution is from the asymptotic value and if the further refinement of the grid will change this solution. Numerical solution at two different grids together with nominal order of accuracy of the numerical scheme is necessary for computing GCI. However, Roache encouraged the idea of using a three or more grid, especially in cases when the observed order of

accuracy differs from the formal order of accuracy. The GCI, formal order of accuracy $p$ and approximate relative error $e_{a}^{21}$ are calculated using Eqs. [33], [34]:

$$
\begin{aligned}
& G C I_{\text {fine }}^{21}=\frac{1.25 e_{a}^{21}}{r_{21}^{p}-1} \\
& p=\frac{1}{\ln r_{21}}|\ln | \varepsilon_{32} / \varepsilon_{21}|+q(p)| \\
& q(p)=\ln \left(\frac{r_{21}^{p}-s}{r_{32}^{p}-s}\right) \\
& s=1 . s g n\left(\varepsilon_{32} / \varepsilon_{21}\right) \\
& e_{a}^{21}=\frac{\phi_{1}-\phi_{2}}{\phi_{1}}
\end{aligned}
$$

where: $\varepsilon_{32}=\phi_{3}-\phi_{2}, \varepsilon_{21}=\phi_{2}-\phi_{1}, \phi_{k}$ denotes the simulated result on the $k^{\text {th }}$ grid. The grid refinement factor $r$ is calculated using the formula:

$$
\begin{aligned}
& r_{32}=\frac{h_{3}}{h_{2}}, r_{21}=\frac{h_{2}}{h_{1}} \\
& h=\left[\frac{1}{N} \sum_{i=1}^{N}\left(\Delta A_{i}\right)\right]^{1 / 2}
\end{aligned}
$$

where: $A$ is the area of the $i^{\text {th }}$ grid elements, and $N$ is the total number of grids points. 


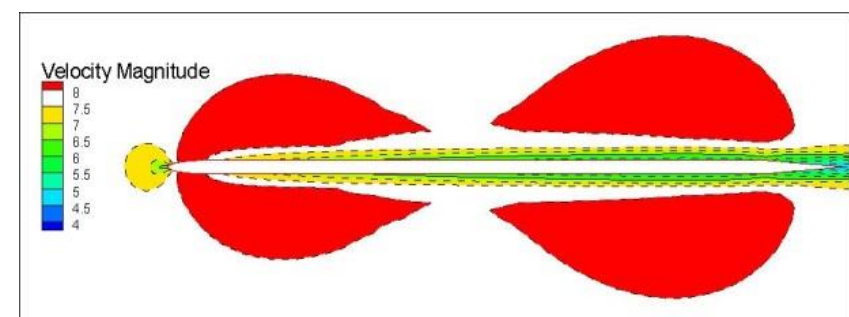

a

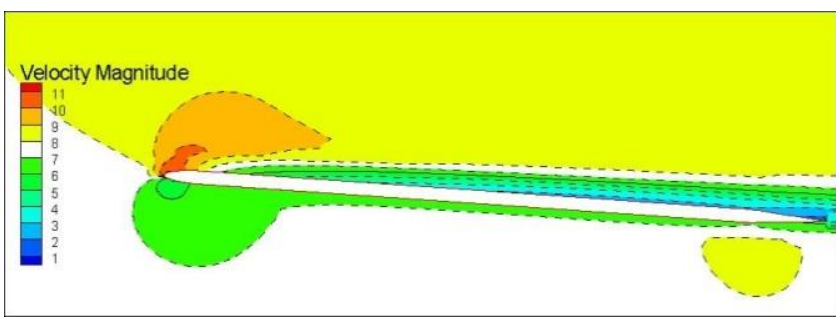

$\mathrm{b}$

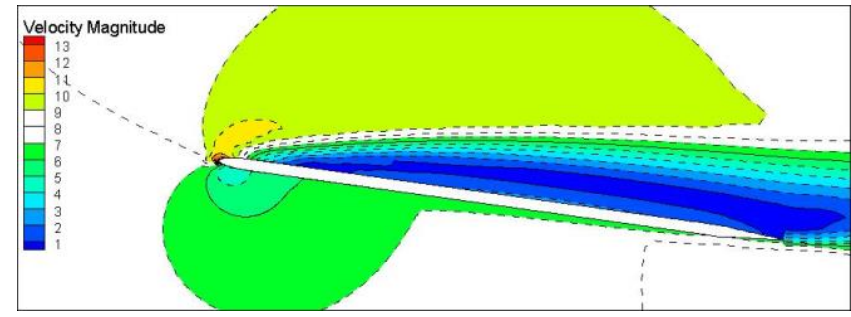

C

Fig. 6 Contours of velocity magnitude at different angles of attack: a) $0^{\circ}$; b) $4^{\circ}$; c) $8^{\circ}$

The order of accuracy $p$ and GCI for the simulation results of drag coefficients on three grids are summarized in the Tables 2. Superscripts 1, 2 and 3 represent coarse, medium and fine mesh respectively. It can be observed from Table 2 that GCI for finer grid $\mathrm{GCI}^{32}$ has relatively small value compared to that of the coarser grid $\mathrm{GCI}^{21}$ indicating a reduced dependency of numerical results on the cell size. Therefore, the further grid refinement will not give a significant change in the numerical results. Since a negligible change in the solution is expected by further mesh refinement, fine mesh (mesh 3 ) is used for all further computations.

Table 2

Order of accuracy and grid convergence index for drag coefficient

\begin{tabular}{|c|c|c|c|c|c|}
\hline $\begin{array}{c}\text { Angle of } \\
\text { attack }\end{array}$ & $e^{21}$ & $e^{32}$ & $p$ & $\mathrm{GCI}^{21}$ & $\mathrm{GCI}^{32}$ \\
\hline $0^{\circ}$ & $2.01 \%$ & $1.21 \%$ & 0.31 & $16.27 \%$ & $14.38 \%$ \\
\hline $2^{\circ}$ & $3.48 \%$ & $1.09 \%$ & 1.57 & $4.13 \%$ & $2.09 \%$ \\
\hline $4^{\circ}$ & $4.64 \%$ & $2.02 \%$ & 0.97 & $10.28 \%$ & $6.89 \%$ \\
\hline $6^{\circ}$ & $4.20 \%$ & $2.01 \%$ & 0.80 & $0.74 \%$ & $0.51 \%$ \\
\hline $8^{\circ}$ & $3.70 \%$ & $0.571 \%$ & 2.87 & $1.69 \%$ & $0.47 \%$ \\
\hline
\end{tabular}

\subsection{Diffuser design and optimization}

In the second stage, the flat plate airfoil is used to design a diffuser for horizontal axis hydrokinetic turbine (parameters summarized in Table 3). Subsequently, the performance of the diffuser is optimized by achieving an optimum curved profile at the internal surface of the diffuser. The Response Surface Methodology (RSM) is used as a tool for optimization. The fluid velocity profile at the throat is chosen as an objective function in this optimization study.

Table 3

Parameters of diffuser

\begin{tabular}{|c|c|}
\hline Parameter & Value \\
\hline Diffuser length & $0.38 \mathrm{~m}$ \\
\hline Inlet diameter & $0.50 \mathrm{~m}$ \\
\hline Incoming flow velocity & $2.75 \mathrm{~m} / \mathrm{s}$ \\
\hline
\end{tabular}

The RSM procedure is carried out as follows:

1) The Bezier curve technique is used to parameterize the airfoil geometry.

2) A $3^{k}$ factorial design is used to create an experimental table containing the combinations of design variables representing the design space.

3) CFD simulations are performed to determine the values of the objective function at each experimental model

4) A full quadratic regression model fitting the numerical data is developed.

5) The optimal set of design variables producing the optimum response value is determined. The schematic flowchart is shown in Fig. 7.

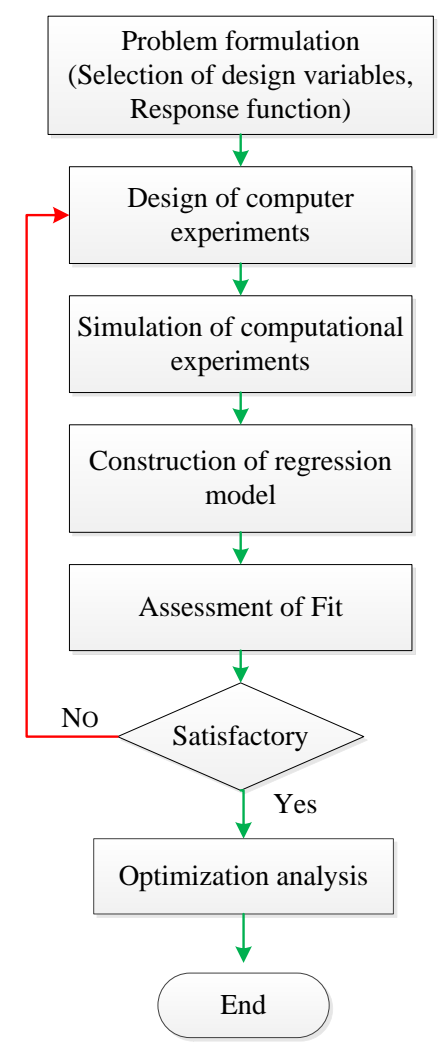

Fig. 7 Optimization flowchart

\subsubsection{Geometric parameterization of airfoil}

Parameterization of the airfoil shape is an important step in the optimization process of any airfoil. In this method, the airfoil is represented by some parameters which control its shape. Over the past few decades, several parameterization techniques have been developed for this purpose. An extensive review of these shape parameterization techniques for airfoils can be found in Ref [35].

In one of the most commonly used parameterization techniques, Bezier curves are used to fit airfoil shapes. A Bezier parameterization of an airfoil is determined by its 
control points. The Bezier curve of order $n+1$ (degree $n$ ) has $n+1$ control points and it passes through the first and last control points which are also the initial and terminal point on the curve itself. [36]

In the present study, a $4^{\text {th }}$ degree Bezier curve was used to fit symmetric flat plate airfoil. The first and last control points, $P_{0}$ and $P_{4}$ lie on the airfoil leading and trailing edges respectively. The position of first point is fixed. The remaining 4 control points are allowed to only move vertically (keeping the abscissas fixed). The following constraint was also set on the y coordinate of control points to obtain different conical diffusers and to maintain a realistic search space.

$$
y_{4} \geq y_{3} \geq y_{2} \geq y_{1} \geq y_{0} \text {. }
$$

\subsubsection{Design of experiments (DOE)}

Design of experiment is an important aspect of RSM and is used to define is a sequence of experiments (numerical simulation in the present case) that will be performed. Since the quality of the response surface is influenced by the choice of points in the design variable space, a careful selection of this method is vital for any optimization study. The most commonly used DOE methods include fullfactorial designs, central composite designs, Box-Behnken designs, Latin Hypercube Design (LHD) and so on.[37]

A $3^{k}$ factorial design is used in the present case to determine the number of required numerical measurements

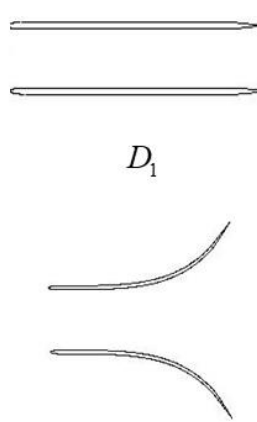

$D_{6}$

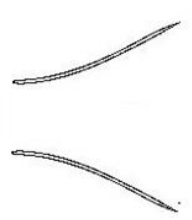

$D_{11}$

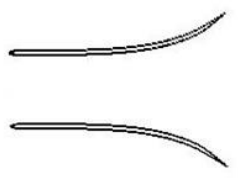

$D_{2}$

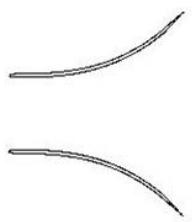

$D_{7}$

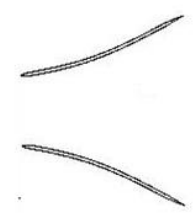

$D_{12}$

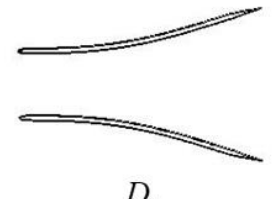

$D_{3}$

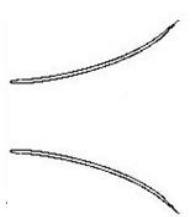

$D_{8}$

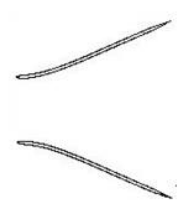

$D_{13}$
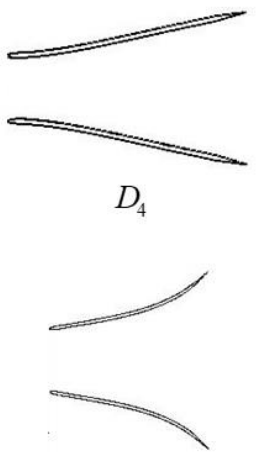

$D_{9}$
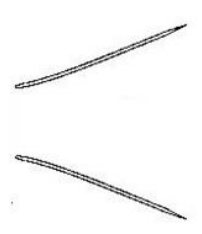

$D_{14}$

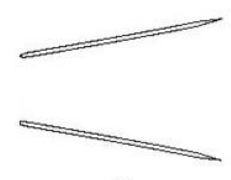

$D_{5}$

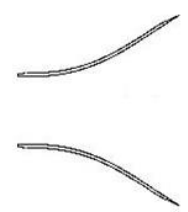

$D_{10}$

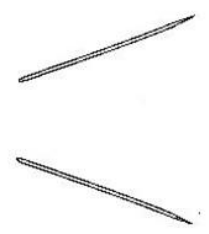

$D_{15}$

Fig. 8 Different diffuser configurations used for CFD analysis

It can be observed that diffuser produced the maximum velocity augmentation of $30.55 \%$ in comparison free stream velocity. The Contours of velocity magnitude inside and around three different diffusers $D_{3}, D_{5}$ and $D_{6}$ are displayed in Fig. 9.

\subsubsection{Model fitting and assessment}

A regression model has been developed to calculate the relationship between fluid velocity at the throat and
4 design variables (control points). The estimated regression line is:

velocity $=3.40-3.52 y_{1}-2.00 y_{2}-1.91 y_{3}+1.60 y_{4}$.

For this relationship, the value of $R^{2}$ (coefficient of determination (often used as a goodness of fit for the model)) is $96 \%$ and adjusted $R^{2}$ is $94 \%$, which shows that the fitted model is a good- fit. Moreover, Table 5 provides the values of the t-test (to check the statistical significance 
of the estimated coefficients) for the corresponding coefficients along with their standard errors. The standard errors are low, and the corresponding p-values shows that the estimated coefficients are statistically significant at 5\% level of significance. Table 6 provide the results of analysis of variance of the estimated model to check the overall adequacy of the model. The corresponding p-value of the F-statistic shows that the model is adequate at $5 \%$ level of significance. The above results show that the estimated model is statistically validated and the predications based on this model should have high reliability.

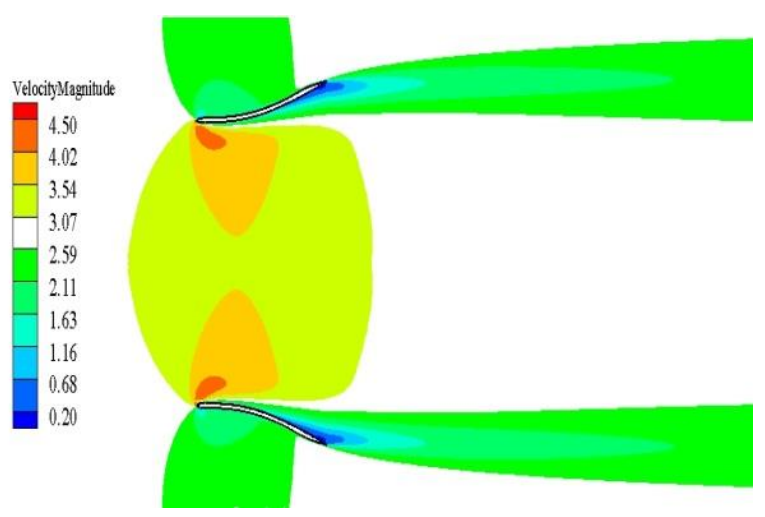

$\mathrm{a}$

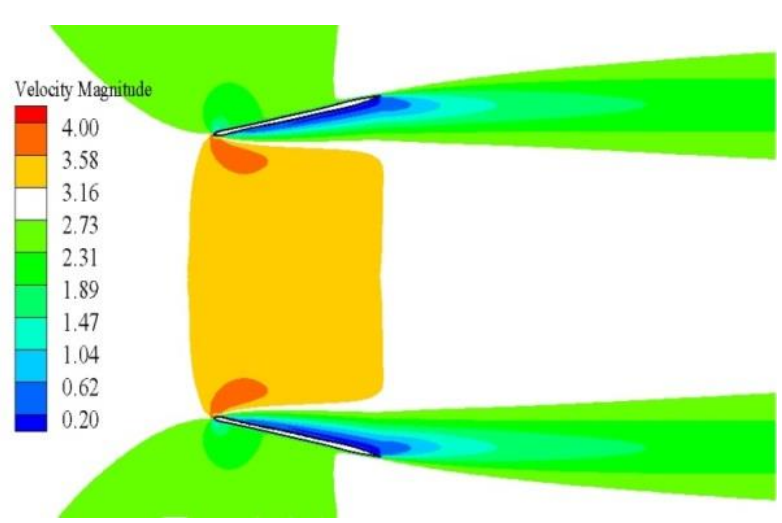

b

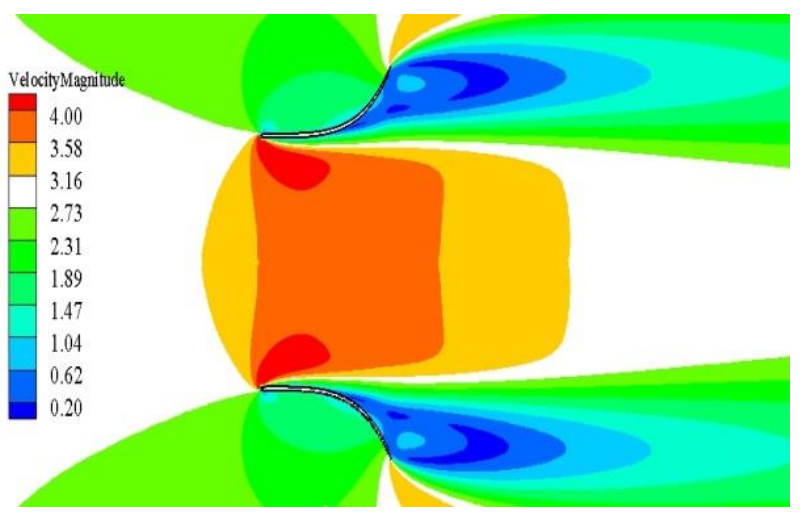

C

Fig. 9 Contours of velocity magnitude inside and around different diffusers a) $D_{3}$; b) $D_{5}$; c) $D_{6}$

\subsubsection{Optimization analysis}

The optimum set of input parameters producing the optimal response value is determined using response optimizer and response surface plots. Fig. 10 is showing the effect of each factor on the response or composite desirability. Here the vertical red and horizontal blue lines represent the current settings and response values respectively. The values of composite desirability lie between 0 and 1 which corresponds to the undesirable and optimal performance for the studied factors response. So the maximum value of composite desirability is showing the occurrence optimal solution. It can be observed from Fig. 10 that the maximum velocity that can be achieved is $3.62 \mathrm{~m} / \mathrm{s}$. Hence, by using optimum geometrical parameters for the diffuser, a velocity augmentation of $31.70 \%$ can be achieved in comparison to the free stream velocity.

Table 5

Coefficients of the estimated regression model with standard errors and t-value

\begin{tabular}{|c|c|c|c|c|}
\hline $\begin{array}{c}\text { Coeffi- } \\
\text { cients }\end{array}$ & Estimates & $\begin{array}{c}\text { SE } \\
\text { (Coefficients) }\end{array}$ & t-value & $\begin{array}{c}\mathrm{p}- \\
\text { value }\end{array}$ \\
\hline Intercept & 3.40 & 0.0320 & 06.26 & 0000 \\
\hline$y_{2}$ & -3.52 & 0.9532 & -3.69 & 0.005 \\
\hline$y_{3}$ & -2.00 & 0.4764 & -4.20 & 0.002 \\
\hline$y_{4}$ & -1.91 & 0.3079 & -6.21 & 0.000 \\
\hline$y_{5}$ & 1.60 & 0.2979 & 5.38 & 0.000 \\
\hline
\end{tabular}

Note: SE (coefficients) is the standard error of coefficients

Table 6

Analysis of variance

\begin{tabular}{|c|c|c|c|c|c|}
\hline Source & $\begin{array}{c}\text { Degrees of } \\
\text { freedom }\end{array}$ & $\begin{array}{c}\text { Sum of } \\
\text { squares }\end{array}$ & $\begin{array}{c}\text { Mean } \\
\text { squares }\end{array}$ & $\begin{array}{c}\text { F- } \\
\text { ratio }\end{array}$ & $\begin{array}{c}\text { P- } \\
\text { value }\end{array}$ \\
\hline $\begin{array}{c}\text { Re- } \\
\text { gres- } \\
\text { sion }\end{array}$ & 4 & 0.2051 & 0.0513 & 55.15 & 0.000 \\
\hline Error & 9 & 0.0084 & 0.0009 & & \\
\hline Total & 13 & 0.2135 & & & \\
\hline
\end{tabular}

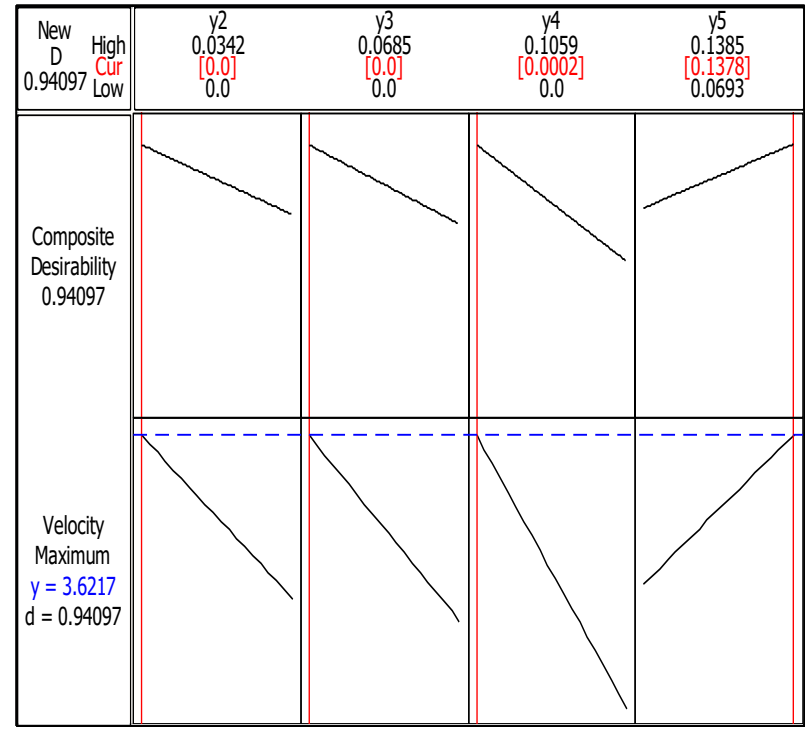

Fig. 10 Response optimizer for the optimum input parameters

\subsection{Performance analysis of optimized diffuser}

The performance of optimized diffuser is analysed using numerical actuator disc approach [38-41]. For this purpose, first the flow around the line projection representing the actuator disc is simulated. In the model setup, the line is assigned a fan boundary condition.

The pressure drop across the whole line is defined using the following relation: 


$$
c_{t}=\frac{P^{+}-P^{-}}{0.5 \rho U^{2}}
$$

here: $\rho$ is density; $U$ is free stream velocity; $C_{\mathrm{t}}$ is thrust coefficient. Contours of the $x$ component of the velocity are displayed in Fig. 11 (a) showing a reduction in velocity followed by the stream tube expansion due to the presence of disk. Fig. 11 (b) shows the effect of the presence of the diffuser in terms of flow augmentation at actuator disc.

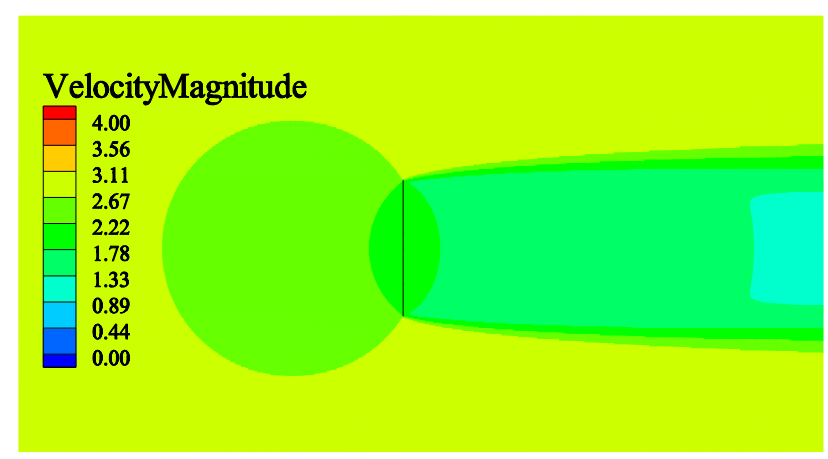

a

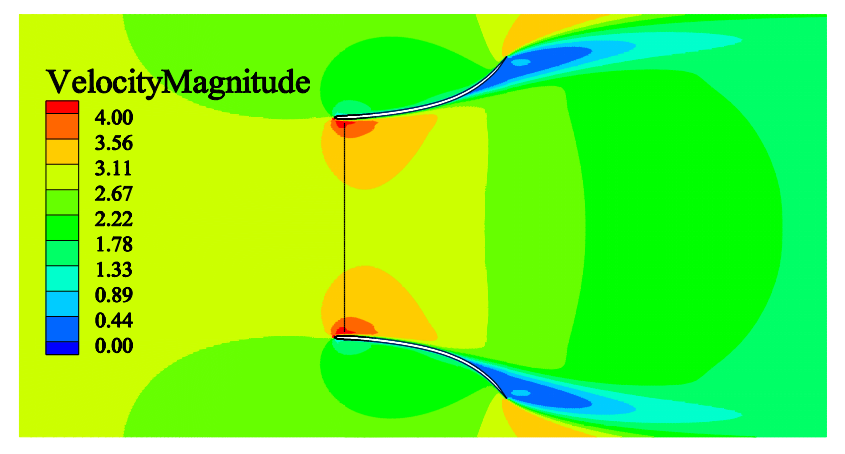

b

Fig. 11 Contours of velocity magnitude around the a) bare disk; b) ducted disk

It can clearly be observed that the diffuser increases axial velocity, when compared to the bare actuator.

\section{Conclusions}

There is an increasing focus on the use of hydrokinetic energy converters since these technologies have the potential to offer a substantial share of the global energy mix. The purpose of this study is the design and optimization of diffuser for horizontal axis hydrokinetic turbine through parametric study using computational fluid dynamics technique.

After numerically validating the baseline case, DOE is used to create fifteen different experiments and corresponding numerical results are analysed using surrogate model to find the optimum geometrical parameters for the diffuser. Later, performance of optimized diffuser is analysed using the actuator disc-RANS model. The important conclusions reached are summarized as follows:

- $\quad$ using a diffuser with optimum curved profile at the internal surface, maximum velocity (at the diffuser throat) that can be achieved is $3.62 \mathrm{~m} / \mathrm{s}$.

- by finding the optimum set of input parameters, a velocity augmentation of $31.70 \%$ can be attained.
- The diffuser with optimum curved profile at the internal surface showed the velocity augmentation of 1.14 times as compared to the straight wall diffuser having almost same area ratio $\left[D_{15}\right]$.

The present study will be extended by performing 3D transient CFD study to analyse effect of diffuser geometry on performance of an actual hydrokinetic turbine. Moreover, turbulence in the inflow effects the performance of diffuser augmented HAHT. The turbulence intensity (TI) is the most commonly used parameter to describe turbulence in marine energy applications. The impact of TI on diffuser augmented HAHT efficiency needs to be investigated.

\section{References}

1. Pachauri, R. K.; Allen, M. R.; Barros, V.R., et al. 2014. Climate change 2014: synthesis report, Contribution of Working Groups I, II and III to the fifth assessment report of the Intergovernmental Panel on Climate Change, IPCC.

https://www.ipcc.ch/site/assets/up-

loads/2018/05/SYR_AR5_FINAL_full_wcover.pdf

2. Khan, M. J.; Iqbal, M. T.; Quaicoe, J. E. 2008. River current energy conversion systems: Progress, prospects and challenges, Renewable and Sustainable Energy Reviews 12(8): 2177-2193. https://doi.org/10.1016/j.rser.2007.04.016.

3. Khan, M. J.; Bhuyan, G.; Iqbal, M. T., et al. 2009. Hydrokinetic energy conversion systems and assessment of horizontal and vertical axis turbines for river and tidal applications: Technology status review, applied energy 86(10): 1823-1835.

https://doi.org/10.1016/j.apenergy.2009.02.017.

4. Güney, M. S.; Kaygusuz, K. 2010. Hydrokinetic energy conversion systems: A technology status review. Renewable and Sustainable Energy Reviews 14(9): 2996-3004. https://doi.org/10.1016/j.rser.2010.06.016.

5. Lago, L. I.; Ponta, F. L.; Chen, L. 2010. Advances and trends in hydrokinetic turbine systems, Energy for Sustainable Development 14(4): 287-296. https://doi.org/10.1016/j.esd.2010.09.004.

6. Yuce, M. I.; Muratoglu, A. 2015. Hydrokinetic energy conversion systems: A technology status review, Renewable and Sustainable Energy Reviews 43: 72-82. https://doi.org/10.1016/j.rser.2010.06.016.

7. Laws, N. D.; Epps, B. P. 2016. Hydrokinetic energy conversion: Technology, research, and outlook, Renewable and Sustainable Energy Reviews 57: 1245-1259. https://doi.org/10.1016/j.rser.2015.12.189

8. Fraenkel, P. L. 2002. Power from marine currents, Proceedings of the Institution of Mechanical Engineers, Part A, Journal of Power and Energy 216(1): 1-14. https://doi.org/10.1243\%2F095765002760024782.

9. Wang, J.; Piechna, J.; Gower, B., et al. 2011. Performance analisys of diffuser augmented composite marine current turbine using CFD, Proceedings of the ASME $5^{\text {th }}$ International Conference on Energy Sustainability (ES'11), 2011. Washington, DC, USA.

10. Werle, M. J.; Presz, W. M. 2008. Ducted wind/water turbines and propellers revisited, Journal of Propulsion and Power 24(5): 1146-1150. https://doi.org/10.2514/1.37134. 
11. Gaden, D. L. F.; Bibeau, E. L. 2006. Increasing Power Density of Kinetic Turbines for Cost-effective Distributed Power Generation, POWER-GEN Renewable Energy Conference, Las Vegas, USA.

http://home.cc.umanitoba.ca/ bibeauel/research/papers/2006_Gaden_powergen.pdf.

12. Kirke, B. 2006. Developments in ducted water current turbines. Tidal paper, 1-12.

http://citeseerx.ist.psu.edu/viewdoc/download?doi=10.1.1.531.3501\&rep=rep1\&type=pdf.

13. Gaden, D. L. F.; Bibeau, E. L. 2010. A numerical investigation into the effect of diffusers on the performance of hydro kinetic turbines using a validated momentum source turbine model, Renewable Energy 35(6):1152-1158.

https://doi.org/10.1016/j.renene.2009.11.023.

14. Shives, M.; Crawford, C. 2010. Overall efficiency of ducted tidal current turbines, Proc., Oceans 2010 MTS/IEEE Seattle, WA, USA, 2010, 1-6. https://doi.org/10.1109/OCEANS.2010.5664426.

15. Sun, H.; Kyozuka, Y. 2012. Analysis of performances of a shrouded horizontal axis tidal turbine, Proc., 2012 Oceans, Yeosu, South Korea, 2012, 1-7.

16. Lokocz, T. A. 2012. Testing of a Ducted Axial Flow Tidal Turbine. Master's thesis, University of Maine, United States.

17. Khunthongjan, P.; Janyalertadun, A. 2012. A study of diffuser angle effect on ducted water current turbine performance using CFD, Songklanakarin Journal of Science \& Technology 34(1): 61-67.

http://rdo.psu.ac.th/sjstweb/journal/34-1/0125-3395-341-61-67.pdf.

18. Mehmood, N.; Zhang, L.; Khan, J. 2012. CFD study of NACA 0018 for diffuser design of tidal current turbines, Research Journal of Applied Science, Engineering and Technology 4(21): 4552-4560.

https://pdfs.seman-

ticscholar.org/7d9e/e17bf0d592653cb956ae888f0070b 53aabca.pdf.

19. Mehmood, N.; Zhang, L.; Khan, J. 2012. Exploring the effect of length and angle on NACA 0010 for diffuser design in tidal current turbines, Applied mechanics and materials, pp. 438-441.

https://doi.org/10.4028/www.scientific.net/AMM.201202.438

20. Mehmood, N.; Zhang, L.; Khan, J. 2012. Diffuser augmented horizontal axis tidal current turbines, Research Journal of Applied Sciences, Engineering and Technology 4(18): 3522-3532. http://maxwellsci.com/print/rjaset/v4-3522-3532.pdf.

21. Luquet, R.; Bellevre, D.; Fréchou, D. et al. 2013. Design and model testing of an optimized ducted marine current turbine, International journal of marine energy 2 : 61-80.

https://doi.org/10.1016/j.ijome.2013.05.009.

22. Shinomiya, L. D.; Aline, D.; Maria, A. et al. 2013. Numerical Study of Flow around Diffusers with Different Geometry Using CFD Applied to Hydrokinetics Turbines Design, Proc., 22nd International Congress of Mechanical Engineering - COBEM 2013, Ribeirão Preto, Brazil.

23. Ait-Mohammed, M.; Tarfaoui, M.; Laurens, J.M. 2014. Predictions of the hydrodynamic performance of horizontal axis marine current turbines using a panel method program. In: Proc., International Conference on Renewable Energy and Power Quality (ICREPQ'14), Cordoba, Spain.

24. Shi, W.; Wang, D.; Atlar, M. et al. 2015. Optimal design of a thin-wall diffuser for performance improvement of a tidal energy system for an AUV, Ocean Engineering 108: 1-9. https://doi.org/10.1016/j.oceaneng.2015.07.064

25. Riglin, J.; Schleicher, W.C.; and Oztekin A. 2015. Numerical analysis of a shrouded micro-hydrokinetic turbine unit, Journal of Hydraulic Research 53(4): 525531. https://doi.org/10.1080/00221686.2015.1032375.

26. Oblas, N. 2016. Design, Manufacture and Prototyping of a Hydrokinetic Turbine Unit for River Application, Master's thesis, Lehigh University, Pennsylvania, USA.

27. Tampier, G.; Troncoso, C.; and Zilic, F. 2017. Numerical analysis of a diffuser-augmented hydrokinetic turbine, Ocean Engineering 145: 138-147. https://doi.org/10.1016/j.oceaneng.2017.09.004.

28. Nunes, M. M.; Mendes, R. C. F.; Oliveira, T. F, et al. 2019. An experimental study on the diffuser-enhanced propeller hydrokinetic turbines, Renewable Energy 133: 840-848. https://doi.org/10.1016/j.renene.2018.10.056.

29. Versteeg, H. K.; Malalasekera, W. 2006. An Introduction to Computational Fluid Dynamics: The Finite Volume Method, $2^{\text {nd }}$ ed, Pearson Education, New York.

30. Najar, N. A.; Dandotiya, D.; Najar, F. A. 2013. Comparative analysis of k-epsilon and spalart-allmaras turbulence models for compressible flow through a convergent-divergent nozzle, International Journal of Engineering and Science 2: 8-17.

http://www.theijes.com/papers/v2i8/Part.2/B028208017.pdf.

31. Kostić, Č. 2015. Review of the Spalart-Allmaras turbulence model and its modifications to three-dimensional supersonic configurations, Scientific Technical Review 65(1): 43-49.

https://doi.org/10.5937/STR1501043K.

32. Gabriel, E. T.; Mueller, T. J. 2004. Low-aspect-ratio wing aerodynamics at low Reynolds number, AIAA Journal 42(5): 865-873.

https://doi.org/10.2514/1.439.

33. Celik, I. B.; Ghia, U.; Roache, P. J, et al. 2008. Procedure for estimation and reporting of uncertainty due to discretization in CFD applications, Journal of fluids Engineering-Transactions of the ASME 130(7): 1-4. https://doi.org/10.1115/1.2960953.

34. Roache, P. J. 1994. Perspective: a method for uniform reporting of grid refinement studies, Journal of Fluids Engineering 116(3). American Society of Mechanical Engineers: 405-413. https://doi.org/10.1115/1.2910291.

35. Samareh, J. A. 2001. Survey of shape parameterization techniques for high-fidelity multidisciplinary shape optimization, AIAA journal, 39(5): 877-884. https://doi.org/10.2514/2.1391.

36. Derksen, R. W.; Rogalsky, T. 2010. Bezier-PARSEC: An optimized aerofoil parameterization for design, Advances in engineering software 41(7-8): 923-930. https://doi.org/10.1016/j.advengsoft.2010.05.002

37. Cavazzuti, M. 2013. Design of Experiments. In: Optimization Methods: From Theory to Design Scientific 
and Technological Aspects in Mechanics, Berlin, Heidelberg: Springer Berlin Heidelberg, pp. 13-42. https://doi.org/10.1007/978-3-642-31187-1_2.

38. Batten, W. M. J.; Harrison, M. E.; Bahaj, A. S. 2013. Accuracy of the actuator disc-RANS approach for predicting the performance and wake of tidal turbines, Philosophical Transactions of the Royal Society A: Mathematical, Physical and Engineering Sciences, 371(1985). https://doi.org/10.1098/rsta.2012.0293.

39. Lartiga, C.; Crawford, C. 2010. Actuator disk modeling in support of tidal turbine rotor testing, Proc. 3rd Int. Conf. on Ocean Energy, Bilbao, Spain, pp. 1-6.

40. Lawn, C. J. 2003. Optimization of the power output from ducted turbines, Proceedings of the Institution of Mechanical Engineers, Part A: Journal of Power and Energy 217(1): 107-117. https://doi.org/10.1243\%2F095765003321148754.

41. Shives, M.; Crawford, C. 2012. Developing an empirical model for ducted tidal turbine performance using numerical simulation results, Proceedings of the Institution of Mechanical Engineers, Part A: Journal of Power and Energy 226(1): 112-125.

https://doi.org/10.1177\%2F0957650911417958.
W. Khalid, S. Sherbaz, A. Maqsood, Z. Hussain

DESIGN AND OPTIMIZATION OF A DIFFUSER FOR

A HORIZONTAL AXIS HYDROKINETIC TURBINE

USING COMPUTATIONAL FLUID DYNAMICS

BASED SURROGATE MODELLING

S u m m a r y

Fossil fuels have remained at the backbone of the global energy portfolio. With the growth in the number of factories, population, and urbanization; the burden on fossil fuels has also been increasing. Most importantly, fossil fuels have been causing damage to the global climate since industrialization. The stated issues can only be resolved by shifting to environment friendly alternate energy options. The horizontal axis hydrokinetic turbine is considered as a viable option for renewable energy production. The aim of this project is the design and optimization of a diffuser for horizontal axis hydrokinetic turbine using computational fluid dynamics based surrogate modeling. The two-dimensional flat plate airfoil is used as a benchmark and flow around the airfoil is simulated using Ansys Fluent. Later, computational fluid dynamics analyses are carried out for baseline diffuser generated from the flat plate airfoil. The performance of this diffuser was optimized by achieving an optimum curved profile at the internal surface of the diffuser. The response surface methodology is used as a tool for optimization. A maximum velocity augmentation of $31.70 \%$ is achieved with the optimum diffuser.

Keywords: renewable energy, hydrokinetic turbine, diffuser augmentation, computational fluid dynamics, fluent.

Received June 02, 2019

Accepted April 15, 2020 